\title{
In a Minor Key: Visual Effects in Shake-Speare's Sonnets
}

\author{
Alan F. Hickman \\ American University in Bulgaria
}

\begin{abstract}
Students of the sonnets are no doubt aware that they abound in wordplay that rewards multiple readings. They may be less aware, especially if they are unfamiliar with the original 1609 Quarto edition, that the poems may have been arranged to have a visual impact as well.

The sonnet form itself is emblematic of a number of familiar referents, including an escutcheon, a "glass" (mirror), a leaf, and a seal. One might even see in the poems, as did Lady Mary Worth and John Donne in their "crowns" of sonnets, the links in a chain, or necklace. The sonnet form is roughly the poetic equivalent to the portrait miniature (a fad of the day) in art. I shall be pursuing these analogies in my paper.

The most striking visual effect occurs in Sonnet 126, the last of the "fair youth" sonnets, which consists of six rhymed couplets followed by two empty sets of brackets. Katherine Duncan-Jones and others have, in recent years, argued authorial intent for this alleged "printer's error." Duncan-Jones suggests that the open parentheses may signify the poet and the fair youth's "failure to couple," while John Lennard sees in them "the silence of the grave."
\end{abstract}

I hope to demonstrate that, by thinking in visual terms, we might one day be able to unlock the story behind the most enigmatic verse sequence in English poetry.

KEYWORDS: Renaissance, England, Shakespeare, sonnet, typography, book design.

\author{
C. ederi 21 (2011): 147-161 \\ https:// doi.org/10.34136/sederi.2011.8
}


Shakespeare's Sonnets have long been admired and studied by poetry enthusiasts from around the globe. They are often considered to be the supreme expression of love, in all its infinite variety, in the English language. The sequence may be unconventional, but when was Shakespeare not? In this paper I will explore the Sonnets from the point of view of their visual effects, with the goal of discovering whether a case might be made for the presence of an authorial hand in their printing. For purposes of getting as close to the originals as possible, I have consulted online facsimile editions of the poems (in particular the Chalmers-Bridgewater copy from the Huntington Library, courtesy of R. G. Siemens) and, where relevant, have reproduced spellings from the original 1609 Quarto $(\mathrm{Q})$.

To begin with the obvious, the text of the quarto - which contains four pages of front matter, the sequence of 154 sonnets (which includes the "Cupid" epigrams) and the "complaint" poem, in rhyme royal - is spread out over 80 pages and 11 signatures (A-L, but missing, as was customary, J). Pages 1-4 include the title page on $\mathrm{A}_{1} \mathrm{r}^{1}$ and the dedication on A2r (A1v and A2v are blank); pages 5-69 (Bir-Kir) are given over to the sonnets themselves; and pages $70-80$ (K1v-L2v) contain the 329 lines of A Lover's complaint. With only three exceptions (Sonnets 99, 126, and 145), the poems consist of 14 lines and are in iambic pentameter verse, each beginning with a large capital letter and ending with an indented, rhymed couplet.

Two ornamental headpieces appear in the quarto: one on the title page and the other on B1r, which begins the sonnet sequence. Numbering of the sonnets starts with Sonnet 2 ("When fortie winters shall besiege thy brow," also on Bir). The sequence concludes with the word FINIS, in caps and followed by a period, with the letters $\mathrm{K}$ (for the signature) and A (for the catchword to A Lover's complaint) beneath. The book itself concludes with the word FINIS, again in caps, followed by a period and an ornamental border. One of the curiosities of the text involves the spelling of Shakespeare's name on the title page; it is as we have come to spell it today, with the addition (found elsewhere) of a hyphen between $s$ and $p$; the hyphen repeats in the headers on the verso pages of the sonnet sequence. It also repeats on the title-page of $A$ Lover's complaint, and in the

\footnotetext{
${ }^{1}$ The abbreviations used by Elizabethan printers for recto and verso are $r$ and $v$.
} 
headers in that section as well, only this time it is accompanied by the author's Christian name, William - its only appearance in the quarto, although the diminutive, Will/will, is punned upon in several of the sonnets, notably 135-136 (both poems are complete on Ilr), where it most often appears in italics. To return to the hyphen in Shake-speares Sonnets, however, James Shapiro (2010:256) alleges, in Contested Will, such a spelling was probably a compositional necessity, given that "when setting a ' $k$ ' followed by a long ' $s$ ' in italic font - with the name Shakespeare, for example - the two letters could easily collide and the font might snap. The easiest solution was inserting a letter 'e,' a hyphen, or both." According to Shapiro, it was "a habit that carried over when setting roman font as well."

I am not directly concerned with whether the publication of the quarto was authorized, although the more we note of "design" in Q, the more difficult it becomes not to discern an authorial hand in its composition. ${ }^{2}$ Instead, I propose to look at the visual features apparent in a handful of sonnets and then to comment on what may be seen as "unifying features" in the design of the sonnet sequence and in that of the quarto itself. Visual, for my purposes, may refer to any typographical or design elements in the poems that are immediately apparent to the naked eye, even in those cases where the eye must first be directed to them. Visual may be used in its customary relation to the poet's imagery as well.

Much speculation has focused on what will here be termed the "clock" sonnets - numbers 12, 52, and 60 - so it is perhaps appropriate to begin with these. The obvious thing to say is that these sonnets appear to have been placed ${ }^{3}$ in $Q$ so as to suggest a correspondence between their subject matter and the number of hours on a clock (Sonnet 12), weeks in a calendar year (52), and "minuites" in an hour (6o). The poet's insistence on marking time in the "clock" sonnets, by way of their number, is a standard of analysis, but the poems contain other visual features as well. In Sonnet 12, for example, lines 1-2 protrude further into the right margin that do lines $3-6$, producing a kind of canopy effect, perhaps

\footnotetext{
${ }^{2}$ For an exploration of the notion that the Sonnets are a "bootleg" of Shakespeare's poems, see Clinton Heylin's So Long as Men Can Breathe (2009).

${ }^{3}$ Don Patterson says "The numerical position of the sonnets often turn[s] out to be a little meta-pun, providing more justification for the belief that we can read the author's hand in [...] the sequence" (2010:40).
} 
as a visual complement to the trees that in Line 6 "which erst from heat did canopy the herd." The poem announces its key image "When I doe count the clock that tels the time" - in its first line. The word clock appears but one more time in $\mathrm{Q}$, in Sonnet 57 . It is surely no coincidence that $5+7=12$.

Subsequent references, in Sonnets 77 and 104, are to a "dial," rather than to a clock, but the poet's choice of time as a theme in the sonnets serves to foreground the image of a clock face, which may be figuratively mirrored in the very outline of each poem. ${ }^{4}$ Sonnet 12 also introduces (by name) the figure of "Time's scythe," which, in various incarnations, ${ }^{5}$ cuts its way across the sequence, as in Sonnet 100 , where this number's Roman counterpart, the numeral $C$, is evocative of the scythe's shape, a suggestion effectively reinforced by the compositional "swipe" taken out of line 11 ("I any, be Satire to decay"), which is radically foreshortened. The figure of the scythe, or sickle, also anticipates the absence of two lines that have been literally lopped off at the end of Sonnet 126, the last of the Fair Youth sequence, and one of the three poems in the sequence that does not conform to the Shakespearean sonnet form. Here, the missing couplet has been replaced by two sets of empty parentheses, or brackets, in which one critic discovers the figure of an hourglass (Kalas 2007:263-264); while another sees in them a "quietus," a product of the Fair Youth's "failure" to couple and produce an heir (Duncan-Jones 2007:366); and yet a third finds "the mute effigy of the rendered youth" (Vendler 1997:538).

Sonnet 52 is one of a sub-sequence that begins with Sonnet 50; it does not, however, as do the other poems in this sub-sequence, concern a journey; rather, it reverts to a theme first treated in Sonnet 48 , that of the speaker's "treasure." The central image in 52 is of a "key," the only mention of which in Q is in line 1 of this sonnet: "So am I as the rich whose blessed key." I shall be returning to keys in due course, but both sonnets, 48 and 52, refer directly to a chest (or casket) said to contain jewels or other "up-locked treasure." In

\footnotetext{
${ }^{4}$ In addition to a mirror and a clock face, I shall identify additional objects that may be suggested by the sonnet form below.

${ }^{5}$ The sevens in Sonnet 77, which is located at the halfway mark into the sequence and whose numbers add up to fourteen, may be said to mirror one another (the word "glass" repeats in lines 1 and 5); they may further represent the repeated figure of a scythe. Indeed, the first two lines of Sonnet 77 are "cut off" from lines 3-14 on E4v.
} 
Sonnet 52, the treasure is compared to "feasts," or "Holy days," as David West (2007:169) calls them: "Like stones of worth they thinly placed are, | Or captaine Jewells in the carconet." The setting of such jewels in a carcanet, or "ornamental collar or necklace" (OED) may remind one of the sequencing of sonnets - as verse jewels - in a corona. Sonnet 52 is placed approximately a third of the way into the sonnet sequence; at two-thirds, we find sonnet 104, which is twice 52 and which is another sonnet concerned with time: three years to be exact, or 156 weeks (which is just two more than the number of poems in the sequence). ${ }^{6}$

Sonnet 60 is perhaps the most visually suggestive of the clock group. Helen Vendler (1997:286) contends the trochees that begin lines 1-2 of Sonnet 6o "draw attention to the hastening of the waves, the attacks by eclipses and by Time, and the countervailing praising by verse." Fair enough; but one may also see the movement of the waves in the alternating long and short lines of the first and second quatrains of Sonnet 6o, which might be said to mimic the tide's ebb and flow as the waves "make towards the pibled shore." Further, quatrain 2 is broken in the Quarto over two pages after line five, a fact which brings both "Crawles" and "Crooked" into relief.7 The "ebb and flow" of the lines in Q2 may thus be said to mimic the vicissitudes of life. The preponderance of " $\mathrm{C}$ " and " $\mathrm{Cr}$ " words, including contend, crown'd, confound, and cruel (and perhaps eclipses as well) may recall the curved blade of the "scythe" in line 12, an image carried over from Sonnet 52.

Any sonnet may be discussed in visual terms, but some images are more fanciful than others. For example, one may see in the numerals that comprise the title, Sonnet 99, the nodding heads of flowers. Plus, I don't think it far-fetched to see in Sonnet 111, perhaps the most narcissistic of the sonnets, a visual pun on "I, I, I." I am not alone in my fancy. At least one writer, Nigel Davies (2010), author of the website The Place $2 B e$, sees in the digits that make up Sonnet 55, which is overstuffed with alliterated " $\mathrm{w}$ " and " $\mathrm{s}$ " sounds, an abbreviation for the very title of the quarto: Shake-speare's

\footnotetext{
${ }^{6}$ Helen Vendler (1997:255) points out that "the word robe is literally hidden inside the word ward-robe" in line 10 of Sonnet 52: "Or as the ward-robe which the robe doth hide."
}

${ }^{7}$ Crawls is spelled without the " $\mathrm{e}$ " as a catchword at the bottom of Eir. 
Sonnets. ${ }^{8} \mathrm{He}$ also "notes" puns on the musical octave (which consists of 12 keys and eight notes) in Sonnets 8 and 128. In examining the Chalmers quarto, I have come to suspect that the monosyllabic widow line ("Thou blind fool love, what doost thou to mine eyes") on Iir that begins Sonnet 137 contains two sets of eyes (my italics). ${ }^{9}$ Moreover, may we not see the outline of a viol or lute in the figure 8 of Sonnet 8, which includes the lines, "Marke how one string sweet husband to an other, | Strikes each in each by mutuall ordering"?

The compact form of the sonnet is instantly recognizable on the page. However, the poet embeds images in the poems that repeat throughout the sequence leading to other, emblematic, associations, such as with those of the clock face or "dial" and carcanet of jewels, both of which are discussed above. Such images may include the portrait miniature (more of which later), the glass (or mirror), the monument (along with epitaph and memorial), the chest (or casket), the sail (Sonnets 80, 86, and 117), the seal, the escutcheon (or coat of arms), and even the theatrical stage - in particular with regard to the discovery space, concealed as it was by elaborate hangings (Gurr and Ichikawa 2000:6-7). But more of this later.

The sonnets may be examined individually, or they may be studied as a sequence. With respect to the latter, Marcy L. North (2007:219), who concedes that there are "vestiges of a manuscript origin" in the quarto, nonetheless suggests that its "patched-together arrangement, lack of an author's epistle, and even the asymmetrical page layout" are "noticeably unconventional" (204). She concludes that the volume "shares some of the characteristics of the highly standardized 1590 sequences, such as quarto formatting, simple numbering of sonnets, and a fore-grounding of sonnets within a multi-genre publication" (208). The fact that more than one sonnet is arranged on a page, and that some are broken over two pages, creates "a kind of forward rhythm that cuts across the thematic divisions and connections in the sequence." One might add that such an arrangement serves to keep the reader turning pages, no small feat considering the number of poems in the sequence. Only the final

\footnotetext{
${ }^{8}$ This sort of "play" reminds me of internet emoticons.

${ }^{9}$ Not all such puns are innocent: Blogger Brooke Marshall (2008) argues for a ribald typographical pun in John Donne's "The Flea" that depends on a confusion between the long $s$ and $f$ in the line, "It suck'd me first, and now sucks thee."
} 
sonnet, Sonnet 154 , which is itself a variation on, or mirror-image of, 153 , is given pride of place on its own page.

Elizabeth D. Harvey further identifies an ordering device involving color: "Readers of Shakespeare's sonnets have noted that the sequence moves along a gamut of color, from the 'fairest Creatures' of the first sonnet to the praise of 'black' in sonnet 127" (2007:314). This movement from white to black is visually complemented by the black ink on the "white" pages of the Quarto itself. The speaker alludes to other colors in the sequence, including "the 'living hue' of the Fair Youth in Sonnet 67 that 'blush[es] through lively veins"' (323), suggesting both the color of the rose (with its bloodlike hue) and the so-called "carnation," or "flesh colour" of the portrait miniature (Coombs 1998:16).

The overall composition of the sonnet sequence is punctuated by certain standard features of book-making in the period. These include the ornaments on Air (the title page), B1r, and L2v. The last of these concludes the complaint poem, so it need not concern us here. However, I find the first two suggestive, especially after having read Bruce R. Smith's The Key of Green (2009)and Patricia Fumerton's "'Secret' Arts: Elizabethan Miniatures and Sonnets" (1986). Between them, these two works give me the temerity to suggest that the choice of headpieces on Air and Bir is not fortuitous. Indeed, both ornaments may be said to "invite" the reader into the text, and not without playing up on certain themes that inform the sonnets themselves. ${ }^{10}$ The compositor's (dare we say Shakespeare's?) precise choice of headpieces may not be significant. Indeed, most of the information I found on them on the web was intended to support someone's claim that Francis Bacon was the true author of the poems and plays. Not a very encouraging note on which to start to my investigation! The headpiece on the title page appears to feature two cupids flanking a possibly crowned, androgynous figure, but it's the "back-to-back" conies that catch Baconian eyes; they see in these figures an anagram of their candidate's name. Looking at the bigger picture, however, and taking the entire mise-en-page (with its titles and publisher's colophon) into consideration, might one not "see" the approximate outline of a Renaissance stage, empty except for the

${ }^{10}$ I had a hard time finding information on the headpieces, and I am indebted to Georgianna Ziegler (2010) of the Folger library, with whom I communicated by email, for information on the use of headpieces in the Renaissance. 
words announcing the title and for the claim that the poems are "Never before imprinted," rather ingeniously playing upon Shakespeare's reputation as a playwright (and actor) and inviting the reader to take part in a drama? The headpiece itself may be said to represent a tapestry or stage hanging, perhaps drawn up to reveal the title in a sort-of discovery space. ${ }^{11}$ The lines that appear beneath the period after "Never before Imprinted." represent the perimeter of the stage.

What then of the second headpiece? Is it doing double-duty as a stage hanging? Perhaps, but Shake-speares Sonnets is a multi-genre text that includes two epigrams (perhaps echoed in the cupids of the first headpiece) and a complaint. The public was invited to a viewing of the non-lyric works of the Quarto as to a drama played out on a public stage. But the 154 poems that make up the sonnet sequence are of a more private, one might even say claustrophobic (with their dramatis personae reduced to two or three players), nature than the Cupid epigrams and complaints, whether autobiographical or not. The second headpiece, which appears in place of a number above Sonnet 1 (and which is a variation on the headpiece used in the 1623 Folio) is said, by R. L. Eagle (1947:38), to feature "a key suspended from the centre urn or vase." He then goes on to list other volumes, by Shakespeare and others, that carry the same headpiece. ${ }^{12}$ This key may well look forward to Sonnet 52, of which we have already spoken, but might it not also refer to the dedication on A2r, which begins "TO.THE.ONLIE.BEGETTER." and which may be said to approximate the shape of a keyhole $?^{13}$ And what attaches to a keyhole but a private space - not a discovery space, such as is found on a public stage, but a bedroom, perhaps, or a casket containing something precious to its owner? Patricia Fumerton (1986:57-59)

\footnotetext{
${ }^{11}$ I am basing my assumption as to what a Renaissance stage might have looked like on engravings such as those by Thomas Rawlings and John Payne, found in Bruce R. Smith's The Key of Green (2009:224).

${ }^{12}$ For whatever reason this particular headpiece was selected, it happens to be the one we fnd in the Quarto; it may have been selected by the compositor because it was the most convenient to hand, but it was selected.

${ }^{13}$ Another interpretation might be that the dedication is so arranged as to suggest one $V$ stacked over a second, the double $V$ 's representing the letter $W$, for William. Elizabethan printers often used two $v^{\prime}$ s to represent $w$ when they ran out of $w$ 's. [Also of interest is Don Paterson's assertion that "if we count W's as two V's" the letters in the dedication add up to (sonnet?) 144 (2010:4).]
} 
relates the story of a meeting between Sir James Melville and Queen Elizabeth I that involves the viewing of a portrait miniature of the Earl of Leicester in her majesty's "bed-chamber." The movement described is from a public space (the palace) to a private space (the bed-chamber) and on to an even more private space, the "cabinet" containing the portrait. A similar passage may be implied by the placement of headpieces at certain liminal or threshold spaces within the quarto itself. The stage hanging represented on the title page opens to reveal a discovery space on Bir; the discovery space, like Elizabeth's bed-chamber, contains a cabinet, this one holding, not portrait miniatures, but the sequence of 154 sonnets. Fumerton herself views the sonnet as a verse counterpart to the portrait miniature:

The leading Elizabethan artists of miniatures and sonnets [...] particularly address problems of self and self-expression, and while in ironic contradiction, find an answer in the same "game" of secrecy: in representing through "public" forms (of ornament, convention, rhetoric) the "private" and "true" self, a representation that necessarily could never be presented. (1986:59)

Rather than a stage hanging, the headpiece to the sonnets (B1r) more closely represents a canopy or curtain panel, such as was used to conceal that most intimate of spaces in the home, a bed. As in the case of Elizabeth and Melville's progress from bed-chamber to cabinet, the poet's sequence takes us from the Fair Youth sonnets to the most intimate sub-sequence of sonnets, numbers 127-152. The parentheses that conclude the Fair Youth sequence ${ }^{14}$ may then be said to conclude one act, while raising the curtain on yet a third space, this one concealing the most private act in the poet's drama, his adulterous affair with the Dark Lady.

A quote from Stephen Greenblatt's Will in the World will suffice to show how natural it is for scholars to resort to the stage as a metaphor when discussing the sonnets (my italics): "the whole enterprise of writing a sonnet sequence precisely involved drawing a translucent curtain - of one of those gauzy fabrics Elizabethans loved - over the scene, so that only shadowy figures are visible to the public" (2004:233-234). He goes on to say:

${ }^{14}$ These may also be explained as a compositor's attempt to sort out the number of lines on the page so they will equal approximately 36 (Atkins 2003:511-12). 
The sonnets are a thrilling, deeply convincing staging of the poet's inner life, an intimate performance of Shakespeare's response to his tangled emotional relationships with a young man, a rival poet, and a dark lady; and the sonnets are a cunning sequence of beautiful locked boxes to which there are no keys, an exquisitely constructed screen behind which it is virtually impossible to venture with any confidence. (249)

Greenblatt insists upon the absence of a key, but might not the $Q$ compositor's design effects, which include the dedication page and the headpieces, have been meant as a compositional "key" to guide readers through the maze of said "boxes"?

Are there precedents for such an assertion? There may well be; perhaps we have just overlooked them. The Renaissance preoccupation with word games and the like is well-grounded in Shakespeare, as Stephen Booth and others have demonstrated, but it hardly stops there. Sir Philip Sidney punned on his own name when he took the sobriquet Astrophil for his sonnet sequence, not published until after his death (1591). Photographs of sonnet quartos by Shakespeare and his contemporaries that appear on G. R. Ledger's (2009) website illustrate the custom of centering the text on the title and dedication pages, in a self-conscious appeal to the visual, often with striking results, as on the title page of a 1591 printing of Astrophil and Stella, with its mirroring effect. In an age of perspective drawing, trompe l'oeil was a favorite effect of artists (take, for example, the Sistine Chapel) and surely would have been known to English book compositors. The compositor's selection of a headpiece for a book necessarily involves a design choice, even if the reason for that choice is economy. I can easily imagine compositors amusing themselves by selecting headpieces and other design effects that might complement themes in the books they were working on. Perhaps this was part of their professional brief? And what headpiece would be more appropriate to a sequence of love poems than one (out of the many available) sporting an image of cupids?

Certain visual effects may suggest a carryover from the printed editions of Shakespeare's plays. I am thinking particularly of the italicizing of certain words for emphasis (Will/will) as a possible clue (or should I say "cue") to the reader of their thematic import. We are now given reason to believe that players' parts (rolls of paper containing an actor's words) might have contained actual stage directions, such as are implied by shared or incomplete lines in the 
text. ${ }^{15}$ Might this practice be echoed in the breaking up of text over two pages or the foreshortening of a line of text for effect in the sonnets? It is probably just a happy coincidence that catchwords function in much the same way as cues on the page.

The sonnet form itself is a "design" choice, this time of the poet. As I have attempted to convey, the sonnet's very shape (suggestive as it is of a portrait miniature, a mirror, a clock face, etc.) may be intended to comment on themes associated with its subject matter, love.

The more we see of design in the poems, the more likely we are to sense a directing hand in their composition. The temptation then becomes to identify that hand as Shakespeare's. The placement of ornaments in book design has been a chief concern of printers at least since the age of illuminated manuscripts. The monks working at Lindisfarne were probably not aware of the commercial potential of books, but by Shakespeare's time, the physical appearance of a book (not to mention its size and cost) could easily affect its success. It is unfortunate that Shakespeare's austere, yet lovely, book came out in the middle of a plague year; otherwise, it might more readily have caught the eye of aesthetically-minded book buyers. The "Shake-speare" name alone - and there it was, trumpeted to high heavens on the title page - did not, as it turns out, guarantee sales.

As mentioned above, Sonnet 154 takes pride of place in the quarto as the second of the Cupid epigrams and the last of the sequence. Ben Crystal (2009:151-52) recounts a friend's suggestion that Shakespeare may have hubristically arrived at the number 154 for his sequence by considering the maximum number of syllables possible in an individual sonnet (Sonnet 20, because of its feminine endings, is just such a sonnet). True or not, Sonnets 153 and 154, the so-called Cupid epigrams have a kind of tacked-on feel for most readers. They are disappointed by their near-pedestrian and redundant quality. It has even been suggested that they might be Shakespearean juvenilia. However, their placement at the end of the sequence makes for a visual bookend to the appearance of the cupids in the headpiece to $Q$, and they conveniently stretch the sequence out in order for it to arrive at that "odd" number, 154. As

${ }^{15}$ No such "parts" for Shakespeare's plays exist. For a full discussion of their possibilities, however, see Simon Palfrey and Tiffany Stern's Shakespeare in Parts. 
Shakespeare's last "word,"they may be anticlimactic, but they do serve to underscore his amatory theme and to function as a kind of entr'acte, if you will, between the intense drama of the sonnets themselves and the lighter fare afforded by the complaint poem.

Appropriately, the last word in Sonnet 154 is love.

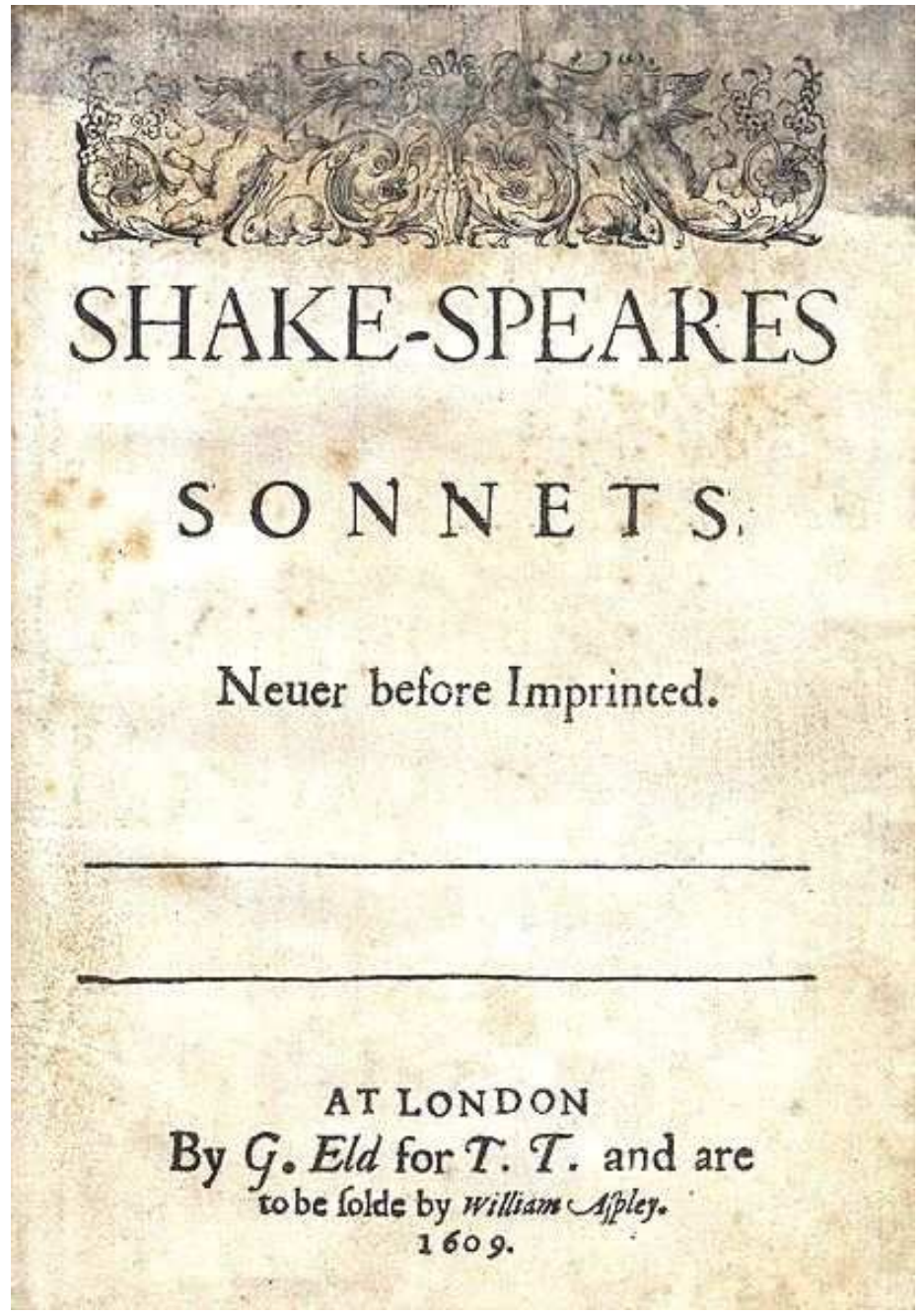

Figure 1. Title page (A1r) of the 1609 Quarto edition of the Sonnets 


\section{TO.THE.ONLIE.BEGETTER.OF.} THESE . INSVING . SONNETS. M.W. H. ALL.HAPPINESSE.

AND.THAT.ETERNITIE. PROMISED.

$$
\text { BY. }
$$

OVR.EVERLIVING.POET.

WISHETH.

THE . WELLWISHING. ADVENTVRER . IN. SETTING. FORTH.

$$
\text { T. T. }
$$

Figure 2. Dedication (A2r) of the 1609 Quarto edition of the Sonnets 


\section{A. Hickman}

\section{References}

Atkins, Carl D. 2004. "The Application of Bibliographical Principles to the Editing of Punctuation in Shakespeare's Sonnets." Studies in Philology 100/4: 493-513. <url: http://www.jstor.org >. Last accessed 18/05/2010.

Booth, Stephen 1977. Shakespeare's Sonnets. New Haven: Yale University Press.

Coombs, Katherine 1998. The Portrait Miniature in England. London: V\&A.

Crystal, Ben 2009. Shakespeare on Toast. London: Icon Books.

Davies, Nigel 2010. "The Sequencing of Shakespeare's Sonnets." The Place 2 B <url: http://www.geocities.com/Athens/Troy/4081/Sonnets.html >._Last accessed 19/05/2010.

Duncan-Jones, Katherine ed. 2007. Shakespeare's Sonnets. London: Arden.

Eagle, R. L. 1947. "The Headpiece on Shakespeare's Sonnets, 1609." Notes and Queries 192/2: 38 .

Fumerton, Patricia 1986. "Secret' Arts: Elizabethan Miniatures and Sonnets." Representations 15: 57-97.

Greenblatt, Stephen 2004. Will in the World: How Shakespeare Became Shakespeare. London: W. W. Norton \& Company.

Gurr, Andrew, and Mariko Ichikawa 200o. Staging in Shakespeare's Theatres. Oxford: Oxford University Press.

Harvey, Elizabeth D. 2007. "Flesh Colors and Shakespeare's Sonnets." Ed. Michael Carl Schoenfeldt. A Companion to Shakespeare's Sonnets. Malden, MA: Blackwell. 314-328.

Heylin, Clinton 2009. So Long as Men Can Breathe: The Untold Story of Shakespeare's Sonnets. Philadelphia: Da Capo Press.

Kalas, Rayna. "Fickle Glass." Ed. Michael Carl Schoenfeldt. A Companion to Shakespeare's Sonnets. Malden, MA: Blackwell. 261-276.

Ledger, G. R. 2009. The Amazing Web Site of Shakespeare's Sonnets. <url: http://www.shakespeares-sonnets.com>. Last accessed 20/05/2010.

Marshall, Brooke 2008. "Typography and Renaissance-Era Eroticism." WPDFD. <url: http://www.wpdfd.com/issues/87/typography-renaissance-era-eroticism >. Last accessed 17/07/2008.

North, Mary. "The Sonnets and Book History." Ed. Michael Carl Schoenfeldt. A Companion to Shakespeare's Sonnets. Malden, MA: Blackwell. 204-221.

Palfrey, Simon, and Tiffany Stern 2007. Shakespeare in Parts. Oxford: Oxford University Press.

Patterson, Don 2010. Reading Shakespeare's Sonnets: A New Commentary by Don Patterson. London, Faber.

Rollins, Hyder Edward ed. 1944. A New Variorum Edition of Shakespeare: The Sonnets. Vol.25 (Part II). Philadelphia: Lippincott.

Schoenfeldt, Michael Carl ed. 2007. A Companion to Shakespeare's Sonnets. Malden, MA: Blackwell.

Shapiro, James 2010. Contested Will: Who Wrote Shakespeare? London: Faber and Faber. 


$$
\text { (G) ederi } 21 \text { (2011) }
$$

Siemens, R. G. 1998. Shakespeare's Sonnets: A Facsimile of the Chalmers-Bridgewater Copy (Aspley Imprint) of the 1609 Quarto, in the Huntington Library. <url: http://extra.shu.ac.uk/emls/Sonnets/Sonnets.html>. Last accessed 19/05/2010.

Smith, Bruce R. 2009. The Key of Green: Passion and Perception in Renaissance Culture. Chicago: University of Chicago Press.

Vendler, Helen 1997. The Art of Shakespeare's Sonnets. Cambridge: Harvard University Press.

West, David 2007. Shakespeare's Sonnets. London: Duckworth Overlook.

Ziegler, Georgianna 2010. Folger Library. Email correspondence. March-April.

How to cite this note:

Hickman, Alan. "In a Minor Key: Visual Effects in Shake-Speare's Sonnets." SEDERI 21 (2011): 147-161.

Author's contact: ahickman@aubg.bg / afhickman@hotmail.com

Submission: 25/10/2010 Acceptance: 14/12/2010 